\title{
An Initial, Three-Day-Long Treatment with Alcohol Induces a Long- Lasting Phenomenon of Selective Tolerance in the Activity of the Rat Hypothalamic-Pituitary-Adrenal Axis
}

\author{
Soon Lee and Catherine Rivier \\ The Clayton Foundation Laboratories for Peptide Biology, The Salk Institute, La Jolla, California 92037
}

\begin{abstract}
We determined whether an initial alcohol challenge induced long-lasting changes in the activity of the hypothalamic-pituitary-adrenal (HPA) axis. Adult male rats received intragastric injections of the vehicle or a moderately intoxicating dose of alcohol $(3.0 \mathrm{gm} / \mathrm{kg})$ daily for $3 \mathrm{~d}$. When animals were acutely challenged with alcohol 3-12 d later, their ACTH and corticosterone responses were significantly blunted, compared with that of vehicle-pretreated rats. In contrast, exposure to mild electric foot shocks induced a pattern of ACTH secretion that was comparable in animals administered alcohol or the vehicle previously, indicating a lack of cross-tolerance. No significant differences were observed in pituitary responsiveness to corticotropin-releasing factor or vasopressin in rats pretreated with the vehicle or alcohol. The influence of the initial drug treatment was not mimicked by exposure to foot shocks, nor was it prevented by administering a potent corticotropinreleasing factor antagonist to block the elevations in plasma $\mathrm{ACTH}$ and corticosterone induced by this initial treatment. Fi-
\end{abstract}

nally, we found that rats injected initially with the vehicle and challenged subsequently with alcohol exhibited the expected increased neuronal activation (measured by the upregulation of steady-state mRNA and protein levels of immediate early genes) in the paraventricular nucleus of their hypothalamus. In contrast, this response was markedly decreased in animals exposed previously to the drug.

To our knowledge, this is the first report that exposure to a stress (i.e., alcohol), although not immediately altering the response of the HPA axis to this particular signal, induces a selective tolerance that is both slow to develop and longlasting. The primary mechanism mediating the ability of an initial drug treatment to decrease subsequent responses of the HPA axis to a second drug challenge seems to be the inability of hypothalamic neurons to respond adequately to this second challenge.

Key words: alcohol; ACTH; corticosterone; c-fos; NGFI-B; PVN; rat
It is well known that an initial exposure of the hypothalamicpituitary-adrenal (HPA) axis to a stress can alter the response of this axis to the same, as well as other, noxious signals. Depending on the nature, intensity, and duration of the initial stimulus, tolerance (habituation) or sensitization develops. Tolerance refers to the situation in which repeated exposure to the same stimulus elicits a diminishing effect on ACTH secretion; sensitization, on the other hand, is observed when repeated treatments elicit a stronger effect on ACTH release than was initially observed.

Hormones of the HPA axis influence many bodily functions. Glucocorticoids (GC), for example, promote the availability of energy substrates (Dallman et al., 1993) and modulate vascular tone (see Munck and Guyre, 1986). After antigenic challenges and once appropriate defense mechanisms have become activated, GC serve to restrain the activity of the immune system and thus prevent it from overshooting (Munck and Guyre, 1986). Corticotropin-releasing factor (CRF), on the other hand, regulates behavior (Koob, 1990) and sympathetic activity (Brown and Fisher, 1990), as well as appetite and gastrointestinal functions

Received June 2, 1997; revised Aug. 26, 1997; accepted Aug. 27, 1997.

This research was supported by National Institutes of Health Grant AA-06420 and the Foundation for Research. We are grateful for the excellent technical assistance of S. Johnson, J. Janas, Y. Haas, H. Wong, and B. D'Arc.

Correspondence should be addressed to Dr. Catherine Rivier, The Clayton Foundation Laboratories for Peptide Biology, The Salk Institute, 10010 North Torrey Pines Road, La Jolla, CA 92037.

Copyright (C) 1997 Society for Neuroscience $\quad 0270-6474 / 97 / 178856-11 \$ 05.00 / 0$
(Taché et al., 1993), immune responses, and reproductive and cardiovascular parameters (see Munck et al., 1984; McEwen, 1992; Rivest and Rivier, 1995). Alcohol administration represents a powerful stimulant of the HPA axis, resulting in increased circulating levels of ACTH and GC, as well as activation of the hypothalamic neurons containing the two peptides that are most important for ACTH release, namely, CRF and vasopressin (VP) (Vale et al., 1981; Rivier et al., 1982; Antoni, 1993). It is therefore obvious that this drug, particularly if it is administered repeatedly, will threaten homeostasis via a variety of mechanisms. In addition, an emerging hypothesis is that hormones of the HPA axis can promote drug use (Cador et al., 1992; Deroche et al., 1993; Piazza et al., 1993; Fahlke et al., 1995; Lamblin and De Witte, 1996; Shaham et al., 1996). Consequently, sensitization to alcohol may reinforce its consumption, whereas, conversely, animals rendered tolerant may attempt to restore normal concentrations of ACTH, corticosterone, and CRF by consuming everincreasing doses of the drug.

We (Rivier et al., 1984; Lee and Rivier, 1993; Rivier, 1996) and others (Spencer and McEwen, 1990) have reported previously that after an initial rise in plasma ACTH and corticosterone levels, continuous exposure to alcohol resulted in a blunting of these responses to the drug itself as well as to other stimuli. What we do not know is whether an initial treatment with alcohol induces long-lasting changes in the activity of the HPA axis that persist after exposure to the drug has ceased. We therefore tested the hypothesis that a first exposure to alcohol would also alter the response of the HPA axis to subsequent challenges. Unexpect- 
Table 1. Weights

\begin{tabular}{llll} 
& \multicolumn{2}{l}{ Weights $(\mathrm{gm})$} & \\
\cline { 2 - 4 } Initial treatment & At arrival & $\begin{array}{l}\text { At end of initial } \\
\text { intragastric } \\
\text { treatment }\end{array}$ & $\begin{array}{l}\text { At time } \\
\text { of second }_{\text {challenge }^{a}}\end{array}$ \\
\hline Vehicle & $181 \pm 7$ & $240 \pm 22$ & $285 \pm 20$ \\
Alcohol & $184 \pm 9$ & $238 \pm 19$ & $282 \pm 21$ \\
\hline
\end{tabular}

$n=5-7$ rats per group.

${ }^{a}$ The experiment was performed $7 \mathrm{~d}$ after the end of the initial intragastric treatment.

edly, we observed a significant blunting of the ACTH and corticosterone responses to a second alcohol challenge, but not to other stimuli, administered 3-12 d after the initial drug treatment. We then determined whether this phenomenon was because of reduced pituitary responsiveness to trophic factors, whether the initial alcohol-induced rise in plasma ACTH and corticosterone levels participated in this altered response, and whether a blunted neuronal response of hypothalamic neurons responsible for ACTH release might account for the decreased effectiveness of the second alcohol challenge.

Many investigators have reported an adaptation of the HPA axis to chronic stress (Dallman, 1993). Most studies have focused on animals that were exposed to a particular stressor immediately after a period of repeated or continuous exposure to this same or another signal (Kant et al., 1985; Akana et al., 1992; Ottenweller et al., 1992; vanRaaij et al., 1997), including work showing adaptation of the HPA axis of rats chronically exposed to alcohol and to the drug itself but not to other stresses (Spencer and McEwen, 1990). To our knowledge, the only report of a long-lasting change in the activity of the HPA axis that persisted once the initial stressor had been removed indicated a prolongation, not a blunting, of the ACTH and corticosterone response to a single injection of the proinflammatory cytokine interleukin-1 (IL-1) (Schmidt et al., 1995). We therefore believe that the present study represents the first example of a phenomenon of selective tolerance that not only develops several days after the initial stimulus has been removed but also persists for a long time.

\section{MATERIALS AND METHODS \\ Animals}

Adult Sprague Dawley male rats were maintained in groups (three to four rats per cage) on a $12 \mathrm{hr}$ light/dark cycle (lights on at 6:00 A.M.). Food and water were available ad libitum.

\section{Cannulae}

Under halothane anesthesia, indwelling intragastric cannulae were inserted at least 1 week before experimentation. Preliminary experiments indicated that it was not necessary to fast the animals before surgery (Ogilvie et al., 1997a). Cannulae were constructed of polyethylene tubing (PE60). The end to be inserted into the stomach was expanded twice to make two bubbled portions, positioned $\sim 5 \mathrm{~mm}$ apart. To place the intragastric cannula, we cut the abdominal wall on the midline and pulled the stomach through this opening. A purse string suture was placed in the nonglandular fundus, after which a hole was opened in the middle of the suture using a pair of spreader forceps. The cannula was passed into the stomach, and the suture was threaded so that it held the cannula between the two bubbled portions of PE tubing to retain the tip in the stomach lumen. With the aid of a trochar, we passed the free end of the cannula through the body wall and under the skin so that it exited at the nape of the neck, where it was capped. After intragastric cannulation, rats were housed individually to prevent chewing of the exteriorized cannula. In experiments requiring blood sampling, intravenous cannulae were inserted $48 \mathrm{hr}$ earlier (Rivier, 1993) .

\section{Treatments}

Alcohol. For the daily alcohol injections, the intragastric cannulae were extended with a PE50 tubing connected to a syringe. Alcohol was diluted with saline to $<20 \% \mathrm{v} / \mathrm{v}$. An equal volume of saline was administered to control rats. During treatment, the rats were awake and freely moving in their home cage. Because the animals were not fasted, alcohol was injected 4-5 hr after lights were turned on, a time when most of the food consumed during the previous night had left the stomach. This treatment schedule also ensured that blood alcohol levels (BALs) had returned to baseline before the animals started feeding again, and indeed alcoholtreated rats maintained normal weight gains (Table 1). Gross examination of the stomach lining failed to indicate any tissue damage, and

\section{O vehicle $3 \mathrm{~g} \mathrm{EtOH} / \mathrm{kg}$, ig}

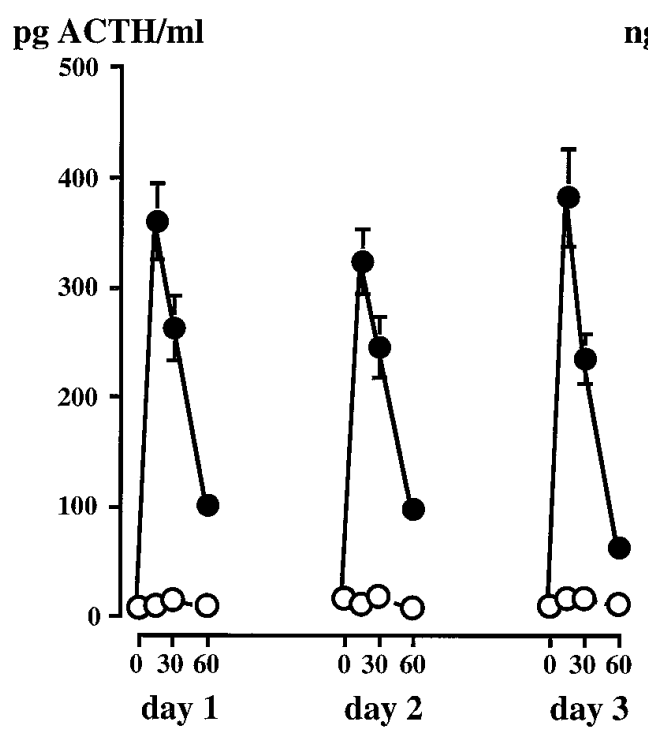

time (min) ng corticosterone/ml

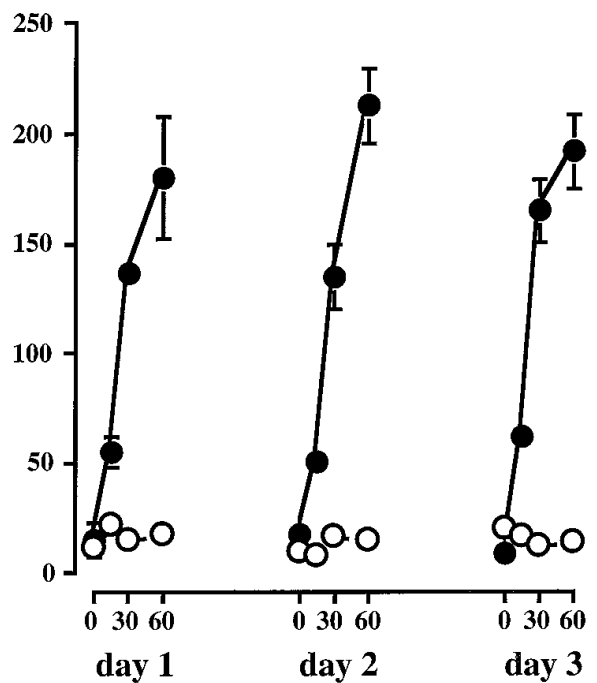

time ( $\mathrm{min})$
Figure 1. Effects of the intragastric (ig) injection of the vehicle $(\bigcirc)$ or alcohol $(\mathbf{Q}, 3.0 \mathrm{gm} / \mathrm{kg})$, administered daily for $3 \mathrm{~d}$, on plasma ACTH and corticosterone levels over a $60 \mathrm{~min}$ time course. Each point represents the mean \pm SEM of five to six intact male rats. For the sake of clarity, no statistical levels of significance are indicated on the figure. However, alcohol-induced changes in hormone levels were significant $(p<$ $0.01)$ at all times indicated. 


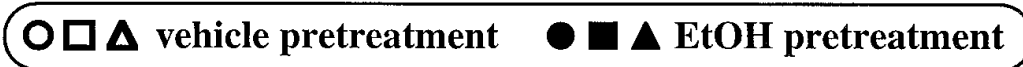

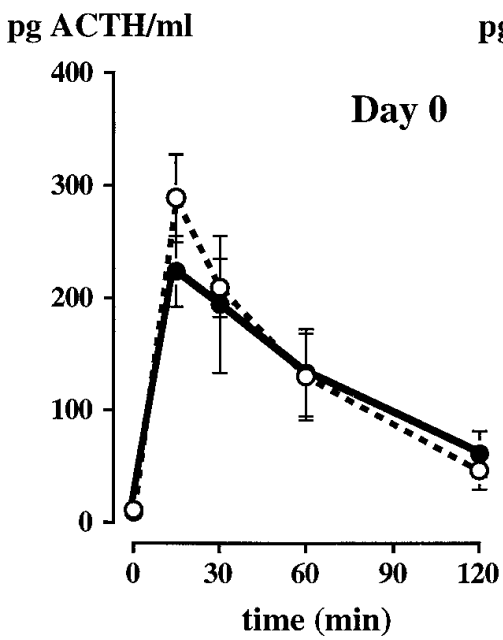

pg ACTH/ml

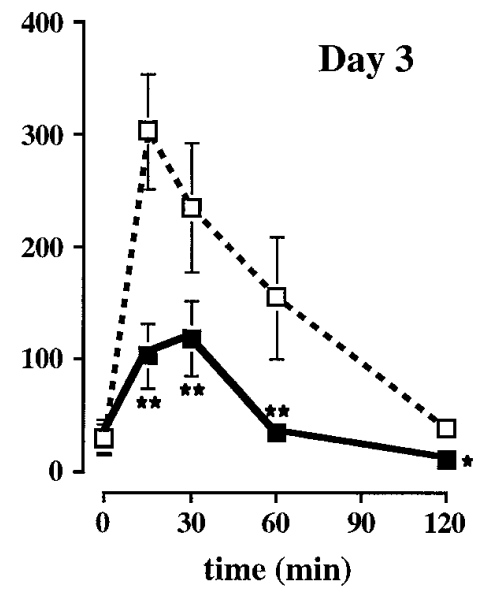

pg ACTH/mI

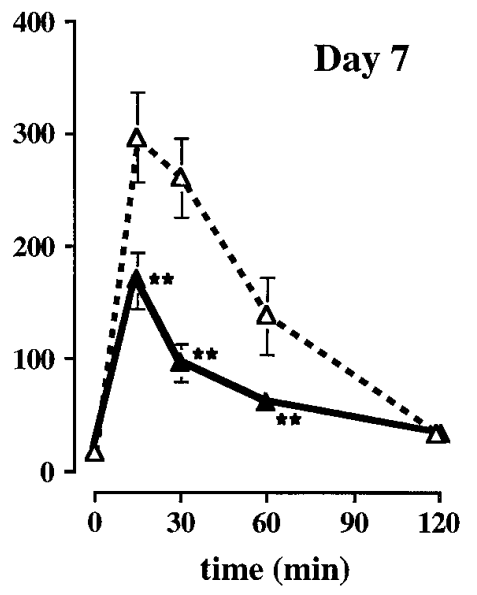

ng corticosterone/ml

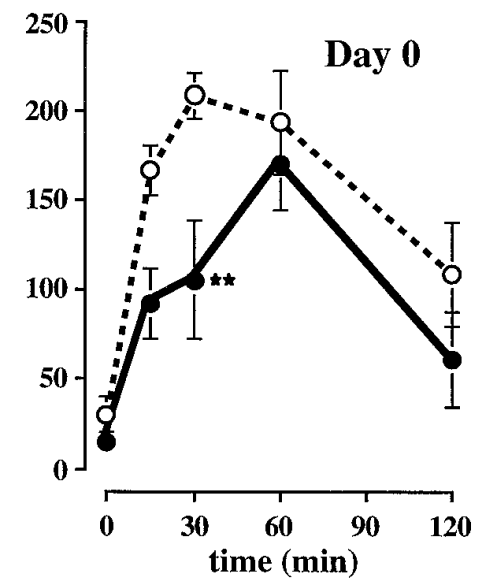

ng corticosterone/ml

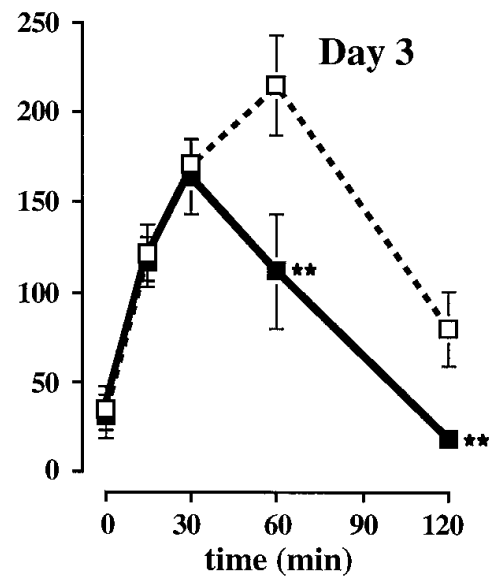

ng corticosterone/ml

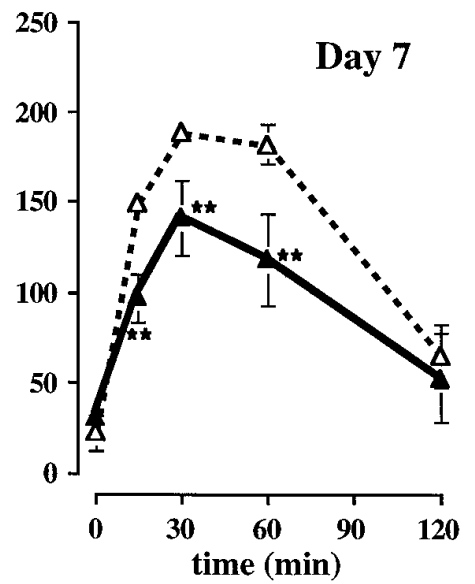

Figure 2. Effects of three consecutive daily intragastric injections of the vehicle or alcohol $(3.0 \mathrm{gm} / \mathrm{kg})$ on the ACTH and corticosterone responses to an acute alcohol challenge $(3.0 \mathrm{gm} / \mathrm{kg})$ delivered 3-7 d later. Day 0 represents the day of the third initial intragastric injection; days 3 and 7 represent the number of days elapsed since the third alcohol injection. Each point represents the mean \pm SEM of six rats $\left({ }^{* *} p<0.01 ;{ }^{*} p<0.05\right)$. A different group of animals was used on days 0,3 , and 7 . For the sake of clarity, the effect of the acute intragastric injection of the vehicle on days 0,3 , and 7 is not shown.

indeed alcohol has been administered through gavage over prolonged periods of time by other investigators (e.g., see Maier et al., 1995). On the day of an experiment, animals were removed to a soundproof room and housed in opaque buckets with cannulae connected such that animals could be injected and bled without being handled. Rats were left undisturbed for $3 \mathrm{hr}$ so that hormone levels would return to basal levels by the time of injection. All experiments began between 11:00 and 12:00 A.M.

Peptides. The potent CRF antagonist astressin (Gulyas et al., 1995) was administered in some experiments to determine whether blockade of the $\mathrm{ACTH}$ and corticosterone responses to the initial alcohol exposure would interfere with the long-term influence of the drug. In other experiments, pituitary responsiveness was determined by administering CRF or VP intravenously at concentrations chosen to provide doserelated increases in plasma ACTH levels (Lee and Rivier, 1995). Peptides were synthesized by solid-phase methodology and generously provided by Dr. Jean Rivier (The Salk Institute, La Jolla, CA). They were diluted in $0.04 \mathrm{M}$ phosphate buffer, $\mathrm{pH} 7.4$, containing $0.1 \%$ bovine serum albumin and $0.01 \%$ ascorbic acid. This vehicle was injected in control rats in the corresponding experiments.

Mild electric foot shocks. These shocks $(1 \mathrm{~mA} ; 1 \mathrm{sec}$ in duration; 2 shocks/min for $30 \mathrm{~min}$ ) were delivered to the paws of the rats as described previously (Rivier and Vale, 1988).
All protocols were approved by the Salk Institute Institutional Animal Care and Use Committee.

\section{Blood alcohol levels (BALs)}

Samples for the measurement of alcohol in whole blood $(100 \mu \mathrm{l})$ were immediately diluted in $6.25 \%$ trichloroacetic acid $(900 \mu \mathrm{l})$ in plastic vials with screw tops (Sarstedt, Nümbrecht, Germany). Samples were stored at $4^{\circ} \mathrm{C}$ until assayed. BALs were measured using a kit purchased from Sigma (St. Louis, MO; 333A), optimized for use with small samples. The coefficient of variation of this method, determined with a serum pool provided by the manufacturer, never exceeded $8 \%$.

\section{cRNA probe synthesis and preparation}

The pBluescript SK-1 vector (Stratagene, La Jolla, CA) containing rat NGFI-B cDNA (provided by Dr. J. Milbrandt, Washington University, St. Louis, MO) or c-fos (provided by Dr. I. Verma, The Salk Institute, La Jolla, CA) was linearized with BamHI or SmaI, respectively. Radioactive cRNA copies were synthesized by incubation of $250 \mathrm{ng}$ of linearized plasmid in $6 \mathrm{mM} \mathrm{MgCl}_{2} ; 36 \mathrm{~mm}$ Tris, $\mathrm{pH} 7.5 ; 2 \mathrm{~mm}$ spermidine; $8 \mathrm{~mm}$ dithiothreitol; $25 \mathrm{~mm}$ ATP, GTP, CTP, and $\alpha^{-}{ }^{35} \mathrm{~S}-\mathrm{UTP} ; 1 \mathrm{U}$ of RNasin (Promega, Madison, WI); and $10 \mathrm{U}$ of $\mathrm{T}_{3}$ (for NGFI-B) or $\mathrm{T}_{7}$ (for c-fos) 

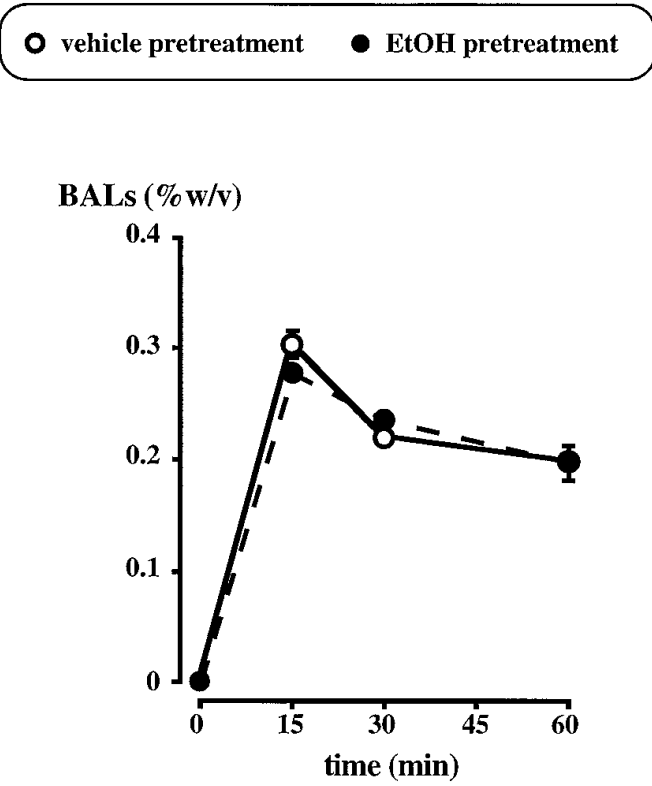

Figure 3. Blood alcohol levels $(B A L s)$ of rats previously administered three consecutive daily intragastric vehicle or alcohol treatments (3.0 $\mathrm{gm} / \mathrm{kg})$ and rechallenged with alcohol $(3.0 \mathrm{gm} / \mathrm{kg}) 7 \mathrm{~d}$ later. Each point represents the mean \pm SEM of six rats.

0 vehicle pretreatment $\bullet$ EtOH pretreatment
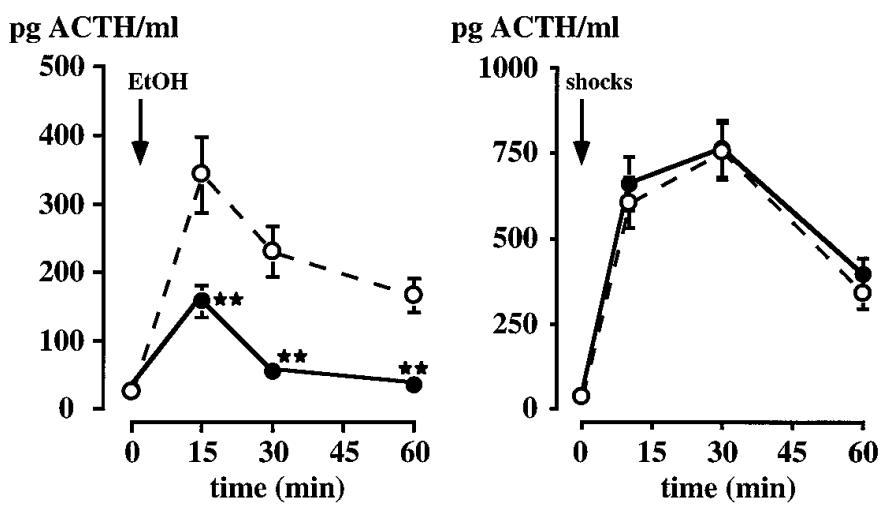

Figure 4. Effects of three consecutive daily intragastric injections of the vehicle or alcohol $(3.0 \mathrm{gm} / \mathrm{kg})$ on the ACTH response to an alcohol challenge $(3.0 \mathrm{gm} / \mathrm{kg})$ or to a $30 \mathrm{~min}$ session of mild electroshocks delivered $7 \mathrm{~d}$ later. Each point represents the mean \pm SEM of six rats $\left({ }^{* *} p<0.01\right)$.

for $60 \mathrm{~min}$ at $37^{\circ} \mathrm{C}$. Unincorporated nucleotides were removed using Quick-Spin columns (Boehringer Mannheim, Indianapolis, IN). A sense probe was used as a control for nonspecific signal in some adjacent sections for in situ hybridization.

\section{In situ hybridization histochemistry}

Four to six rats per group were deeply anesthetized with $35 \%$ chloral hydrate, a drug that does not increase immediate early gene RNA levels or ACTH concentrations. The animals were then perfused transcardially with saline followed by $4 \%$ paraformaldehyde and $0.1 \mathrm{~m}$ borate buffer, $\mathrm{pH} 9.5$. The brains were removed, post-fixed in $4 \%$ paraformaldehyde for 4-5 d, and then placed overnight in $10 \%$ sucrose, $4 \%$ paraformaldehyde, and $0.1 \mathrm{~m}$ borate buffer. They were cut into $30 \mu \mathrm{m}$ coronal slices obtained at $120 \mu \mathrm{m}$ intervals throughout the hypothalamus and stored at $-20^{\circ} \mathrm{C}$ in a cryoprotectant solution (50\% 0.1 M PBS, $30 \%$ ethylene glycol, and $20 \%$ glycerol) until histochemical analysis. vehicle pretreatment EtOH pretreatment $\square$ shocks pretreatment

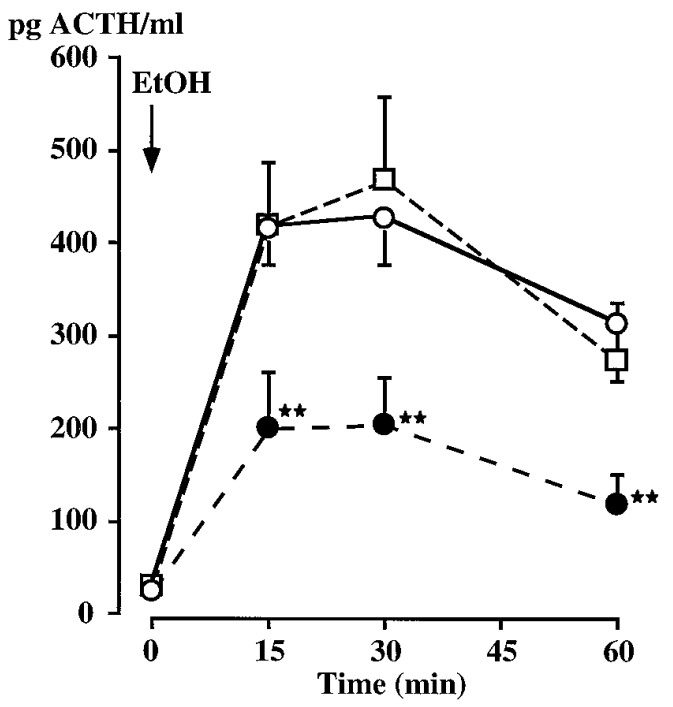

Figure 5. Comparison between the effects of an initial course of alcohol injections $(3.0 \mathrm{gm} / \mathrm{kg}$, i.g.) or shock sessions $(30 \mathrm{~min})$, each delivered daily for 3 consecutive days, on the ACTH response to an acute alcohol treatment $(3.0 \mathrm{gm} / \mathrm{kg})$ administered $12 \mathrm{~d}$ later. Each point represents the mean \pm SEM of six to seven rats $(* * p<0.01)$.

Hybridization histochemical localization of each transcript was performed using ${ }^{35}$ S-labeled cRNA probes. Protocols for riboprobe synthesis, hybridization, and autoradiographic localization of mRNA signals were adapted from Simmons et al. (1989). Brains from the same experiments were always processed and analyzed in the same hybridization experiment. All solutions were treated with diethylpyrocarbonate (Dep. C) and sterilized to prevent RNA degradation. Sections mounted onto gelatin- and poly-L-lysine-coated slides were desiccated under vacuum overnight, fixed in $4 \%$ paraformaldehyde for $30 \mathrm{~min}$, and digested by proteinase $\mathrm{K}(10 \mu \mathrm{g} / \mathrm{ml}$ in $50 \mathrm{~mm}$ Tris $\mathrm{HCl}, \mathrm{pH} 7.5$, and $5 \mathrm{~mm}$ EDTA at $37^{\circ} \mathrm{C}$ for $25 \mathrm{~min}$ ). Thereafter, brain sections were rinsed in sterile Dep. $\mathrm{C}$ water followed by a solution of $0.1 \mathrm{~m}$ triethanolamine (TEA), $\mathrm{pH} 8.0$, acetylated in $0.25 \%$ acetic anhydride in $0.1 \mathrm{M}$ TEA, and dehydrated via graded concentrations of alcohol (50, 70, 95, and 100\%). After vacuum drying for a minimum of $2 \mathrm{hr}, 90 \mu \mathrm{l}$ of hybridization mixture $\left(10^{7}\right.$ $\mathrm{cpm} / \mathrm{ml}$ ) was spotted on each slide, sealed under a coverslip, and incubated at $60^{\circ} \mathrm{C}$ overnight in a slide warmer. Coverslips were then removed, and the slides were rinsed in $4 \times \mathrm{SSC}$ at room temperature. Sections were digested by RNase A $\left(20 \mu \mathrm{g} / \mathrm{ml} ; 37^{\circ} \mathrm{C} ; 30 \mathrm{~min}\right)$, rinsed in descending concentrations of SSC $(2 \times, 1 \times$, and $0.5 \times)$, washed in $0.1 \times$ SSC for 30 min at $65^{\circ} \mathrm{C}(1 \times \mathrm{SSC}, 0.15 \mathrm{M} \mathrm{NaCl}$, and $15 \mathrm{~mm}$ trisodium citrate buffer, $\mathrm{pH}$ 7.0), and dehydrated via graded concentrations of alcohol. After being dried under the vacuum, sections were exposed at $4^{\circ} \mathrm{C}$ to $\mathrm{x}$-ray film (Eastman Kodak, Rochester, NY) for $15 \mathrm{hr}$, defatted in xylene, and dipped in NTB2 nuclear emulsion (Kodak; diluted 1:1 with distilled water). Slides were exposed for $6 \mathrm{~d}$, developed in D19 developer (Kodak) for $3.5 \mathrm{~min}$ at $15^{\circ} \mathrm{C}$ and fixed in rapid fixer (Kodak) for $6 \mathrm{~min}$. Thereafter, tissues were rinsed in running distilled water, counterstained with thionin $(0.25 \%)$, dehydrated via graded concentrations of alcohol, cleared in xylene, and coverslipped with a mixture of distrene, tricresyl phosphate, and xylene (DPX).

\section{Quantitative analysis of in situ hybridization results}

Semiquantitative densitometric analyses of hybridization signals for RNAs of interest were performed on nuclear emulsion-dipped slides. Brain paste standards containing serial dilutions of ${ }^{35} \mathrm{~S}-\mathrm{UTP}$, used for quantification of mRNA signals, were prepared concurrently to ensure that optical density was found within the linear range of the standard curve. In addition, analyses with emulsion-coated slides were performed with two to three different exposure times to confirm that signals were not saturated. Densitometric analyses of autoradiographic signals were 
Figure 6. Effects of three consecutive daily injections of the vehicle (i.g.), the CRF antagonist (astressin at 10 $\mathrm{mg} / \mathrm{kg}$, s.c.), alcohol (3.0 gm $/ \mathrm{kg}$, i.g.), or alcohol preceded 60 min earlier by astressin on the ACTH response to an alcohol challenge $(3.0 \mathrm{gm} / \mathrm{kg})$ delivered $7 \mathrm{~d}$ later. Because results from rats administered the vehicle or astressin were comparable, only those pertaining to vehicle injection are shown. Results illustrate summation of ACTH levels at 15 and 30 min after the second drug challenge. Each point represents the mean \pm SEM of six rats $(-, p>$ $0.05 ;{ }^{* *} p<0.01$ from vehicle-pretreated rats). For the sake of clarity, the effect of acute vehicle injection (second challenge) is not shown.
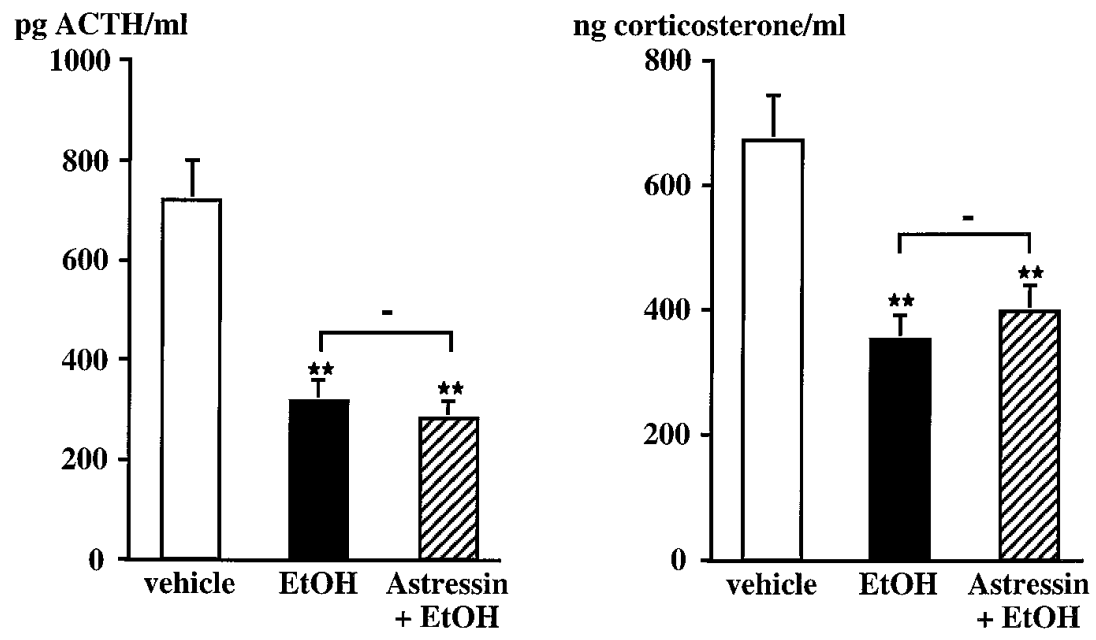

done over the confines of cells within the paraventricular nucleus (PVN), using a Leitz optical system coupled to a Macintosh II computer and Image software (version 1.60; W. Rasband, National Institutes of Health). For statistical analysis, the parvocellular (pPVN) and magnocellular divisions of the PVN (mPVN) were first delineated in each section under bright-field illumination at the rostral and caudal level, and optical density was measured under dark-field illumination as described previously (Ogilvie et al., 1997a,b). Although it is possible to exclude magnocellular neurons scattered in the pPVN region, we did not use this method. It thus remains possible that counts throughout the medial pPVN included some magnocellular neurons. Gray level measurements (optical density) were taken under dark-field illumination of hybridized sections over the medial pPVN, as defined by redirected sampling from the corresponding Nissl-stained sections under bright-field images. Data were expressed in gray scale values of 1-256. All gray level measurements were corrected for background. Signals were measured in both sides of the brain, and mean values for all animals (four to six per group) were determined for each rat in three to four sections throughout the PVN.

\section{Immunohistochemistry}

Series of brain sections were washed in 0.05 M KPBS and incubated 10 min in $0.3 \% \mathrm{H}_{2} \mathrm{O}_{2}$. Sections were then incubated at $4^{\circ} \mathrm{C}$ for $48 \mathrm{hr}$ with primary antiserum applied at a 1:20,000 dilution. Fos immunoreactivity was localized using polyclonal antisera raised in rabbits against a synthetic N-terminal fragment (residues 4-17) of human c-fos (Oncogene Sciences). Next, the sections were incubated with a biotinylated antirabbit IgG (1:1500 dilution; Vector Laboratories, Burlingame, CA) and subsequently incubated at room temperature with a conventional nickelenhanced avidin-biotin immunoperoxidase complex (Vetastain ABC Elite reagents). After the reaction, the sections were mounted onto gelatin-chrome alum-coated slides and coverslipped with DPX.

\section{$R I A s$}

Plasma ACTH levels were measured in duplicate using a two-site immunoradiometric assay (Allegro kit; Nichols Institute, San Juan Capistrano, CA), which we have validated for rat ACTH (Rivier and Shen, 1994). Total corticosterone was measured by double-antibody RIA. The primary antibody was anti-corticosterone-3-BSA (377; G. Niswender, Fort Collins, CO) diluted to give a final concentration of 1:30,000. The sensitivity and coefficient of variation of this assay were $4 \mathrm{ng} / \mathrm{ml}(0.022$ ng/tube) and $<15 \%$, respectively.

\section{Statistical analysis}

Results were analyzed by one- or two-way ANOVA. Student-NewmanKeuls tests were then used to determine differences between treatments. Levels of NGFI-B or c-fos mRNA in the pPVN and mPVN were subjected to a two-way ANOVA, with time after injection of alcohol and pretreatment as the variables. When differences were indicated by the ANOVA procedure, the least squares means test was used for post hoc analysis.

\section{RESULTS}

\section{Effect of an initial exposure to alcohol on the hormonal response to a second alcohol challenge delivered 3-7 d later}

The first set of experiments was designed to investigate the influence of single or repeated alcohol injections on the ACTH and corticosterone responses to a second alcohol challenge. The vehicle or alcohol $(3.0 \mathrm{gm} / \mathrm{kg})$ was injected intragastrically either once or daily for 3 consecutive days. The ACTH and corticosterone responses were comparable whether alcohol was administered once or daily for $3 \mathrm{~d}$ (Fig. 1). Three to seven days after either the single injection or the last of the three injections, the animals received an acute intragastric injection of the vehicle or alcohol (3.0 gm/ kg), yielding four experimental groups: vehicle/ vehicle; vehicle/alcohol; alcohol/vehicle; and alcohol/alcohol. Serial blood samples were obtained over a $120 \mathrm{~min}$ period after the second (acute) treatment. Plasma ACTH and corticosterone levels of the vehicle/vehicle and alcohol/vehicle groups remained at baseline concentrations (data not shown). A single initial alcohol injection did not significantly alter the course of ACTH and corticosterone release induced by the second drug challenge administered 3-7 d later (data not shown). In contrast, rats initially injected with alcohol daily for $3 \mathrm{~d}$ showed significantly $(p<0.01)$ blunted neuroendocrine responses when rechallenged with the drug 3-7 d later (Fig. 2). Interestingly, the patterns of ACTH and corticosterone secretion after the third daily alcohol injection were comparable in vehicle- and alcohol-pretreated rats, indicating that tolerance had not yet developed. There was no obvious difference between the magnitude of this blunting at the various test times (i.e., 3 or $7 \mathrm{~d}$ after the initial alcohol treatment). BALs were statistically comparable after all alcohol injections (Fig. 3).

In a second set of experiments, we determined whether a smaller dose of alcohol [1.5 gm/ kg, intragastrically (i.g.), daily for $3 \mathrm{~d}$ ] would also blunt the response of the HPA axis to the second 

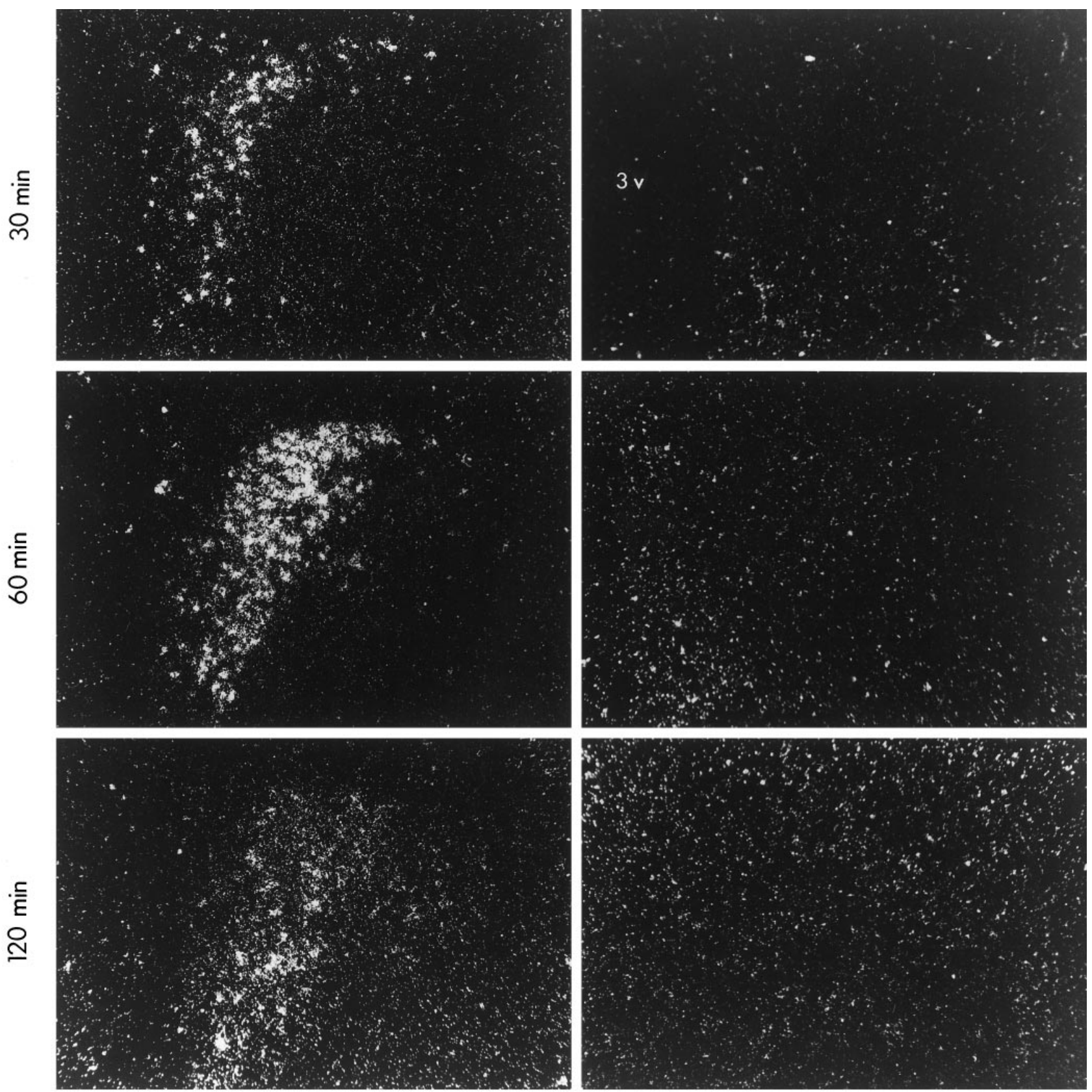

\section{Vehicle}

\section{$\mathrm{E} \mathrm{OH}$}

Figure 7. Effects of three consecutive daily intragastric injections of the vehicle or alcohol $(3.0 \mathrm{gm} / \mathrm{kg})$ on steady-state mRNA levels of the immediate early gene NGFI-B in the PVN of rats injected with alcohol $(3.0 \mathrm{gm} / \mathrm{kg}) 7 \mathrm{~d}$ later. Dark-field photomicrographs illustrating NGFI-B mRNA levels in the PVN of rats injected with alcohol 30, 60, or 120 min earlier are shown. $3 v$, Third ventricle. Magnification, $340 \times$.

alcohol challenge (using our standard dose of $3.0 \mathrm{gm} / \mathrm{kg}$ ) and found that such was not the case (data not shown).

\section{Effect of an initial exposure to alcohol on the hormonal response to mild electric foot shocks delivered 7 d later}

Rats were injected with the vehicle or alcohol $(3.0 \mathrm{gm} / \mathrm{kg})$ daily for 3 consecutive days and submitted to either an alcohol challenge $(3.0 \mathrm{gm} / \mathrm{kg})$ or mild electric foot shocks $(30 \mathrm{~min}) 7 \mathrm{~d}$ later. The initial alcohol treatment induced the expected blunted ACTH response after rechallenge with the drug but did not significantly alter the response to the shocks (Fig. 4). It should be mentioned that although in the experiment illustrated here the ACTH response to shocks was higher than that to alcohol, a subsequent experiment, conducted with shocks of lower intensity, indicated a similar lack of cross-tolerance to foot shocks in alcohol-pretreated rats. These results suggest that there was no ceiling effect that might have masked the development of tolerance to the shocks.

\section{Effect of an initial exposure to mild electric foot shocks on the hormonal response to an alcohol challenge delivered $12 \mathrm{~d}$ later}

This experiment was performed to determine whether previous exposure to foot shocks would mimic the effect of the initial 

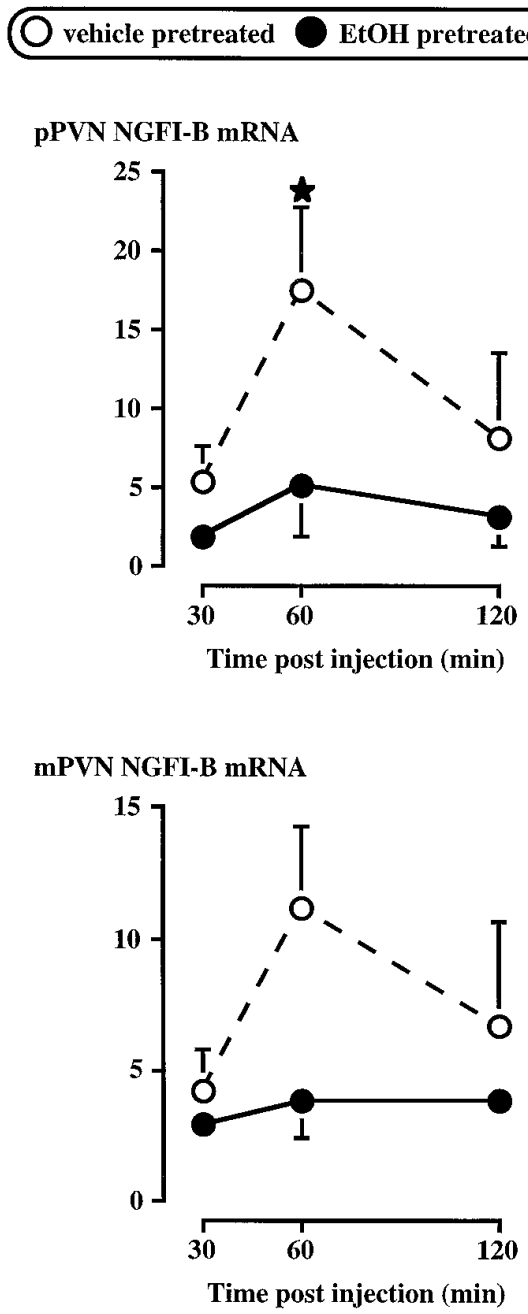

Figure 8. Statistical analysis of the results presented in Figure 7. The optical densities of the pPVN and mPVN were analyzed separately as described in Materials and Methods. Each bar represents the mean \pm SEM of four to six rats $\left({ }^{*} p<0.05\right)$.

alcohol treatments. The animals were either injected with the vehicle or alcohol (3.0 gm/ kg, i.g.) as described for Figures 1 and 2 or exposed to mild electric foot shocks ( $30 \mathrm{~min}$ ) daily for $3 \mathrm{~d}$. The $30 \mathrm{~min}$ shock paradigm we chose induces a pattern of ACTH levels that resembles the hormone profile induced by the intragastric injection of EtOH at $3.0 \mathrm{gm} / \mathrm{kg}$ (C. Rivier, unpublished observations). Five, 7, 9, or $12 \mathrm{~d}$ after the last drug treatment or shock session, the animals were injected with the vehicle or alcohol $(3.0 \mathrm{gm} / \mathrm{kg}$, i.g.). Animals originally administered alcohol and later rechallenged with the drug showed the expected blunting of their ACTH response (Fig. 5). Because results were similar at the $5-12$ d time points, Figure 5 only shows data obtained on the 12 th day. In contrast, rats originally exposed to shocks and subsequently injected with alcohol exhibited a pattern of ACTH release that was comparable with that of control animals.

\section{Changes in pituitary responsiveness to CRF or VP in rats exposed previously to alcohol}

The observation that an initial alcohol challenge did not significantly alter the subsequent ACTH response to electroshocks suggested that pituitary responsiveness to CRF was probably not vehicle pretreated EtOH pretreated
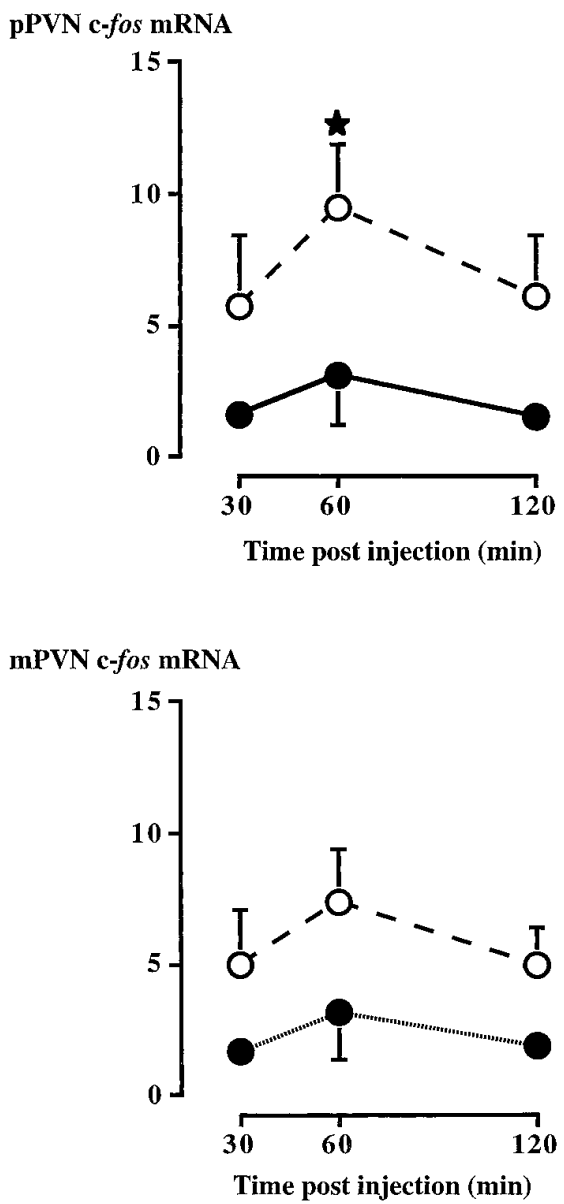

Figure 9. Effects of three consecutive daily intragastric injections of the vehicle or alcohol $(3.0 \mathrm{gm} / \mathrm{kg})$ on steady-state mRNA levels of the immediate early gene c-fos in the PVN of rats injected with alcohol (3.0 $\mathrm{gm} / \mathrm{kg}$ ) $7 \mathrm{~d}$ later. The optical densities of the pPVN and mPVN were analyzed separately as described in Materials and Methods. Each bar represents the mean \pm SEM of four to six rats $\left({ }^{*} p<0.05\right)$.

significantly diminished. Nevertheless, a dose-response curve to CRF was generated in both vehicle-treated rats and rats pretreated with alcohol $7 \mathrm{~d}$ earlier. It indicated that, as expected, the ACTH response to the intravenous injection of CRF at $0.2,1$, or $5 \mu \mathrm{g} / \mathrm{kg}$, measured 10 and $30 \mathrm{~min}$ after peptide administration, was statistically comparable in both experiment groups (data not shown). We had shown previously that rats exposed to an alcohol diet for 7-10 d displayed a significantly decreased ACTH secretory pattern when injected with VP at the end of the diet treatment (Lee and Rivier, 1995). We therefore also investigated the possibility that pituitary responsiveness to VP might similarly be decreased in the present paradigm. However, there was no significant difference $(p>0.05)$ in baseline ACTH levels in rats pretreated with the vehicle $(6.23 \pm 0.82 \mathrm{pg} / \mathrm{ml} \mathrm{ACTH})$ or alcohol at $3.0 \mathrm{gm} / \mathrm{kg} 7 \mathrm{~d}$ earlier $(6.30 \pm 0.74 \mathrm{pg} / \mathrm{ml} \mathrm{ACTH})$ or in the cumulative ACTH responses to the injection of $\mathrm{VP}$ at $0.5,1.5$, or $4.5 \mu \mathrm{g} / \mathrm{kg}$, measured at the 10 and $20 \mathrm{~min}$ time points (vehiclepretreated, $190 \pm 21,499 \pm 45$, and $1130 \pm 120 \mathrm{pg} / \mathrm{ml} \mathrm{ACTH}$, respectively; alcohol-pretreated, $211 \pm 22,543 \pm 49$, and $1079 \pm$ $115 \mathrm{pg} / \mathrm{ml}$ ACTH, respectively). 


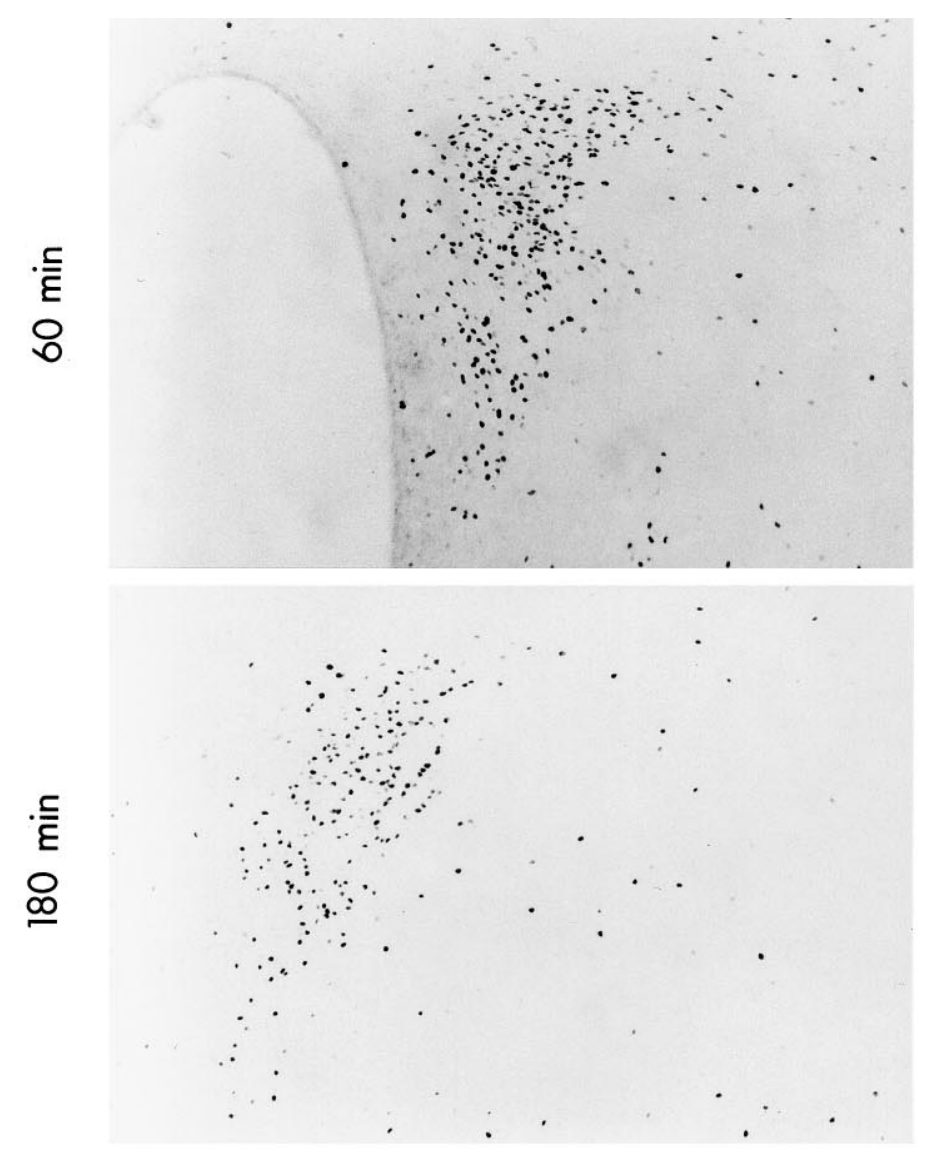

Vehicle

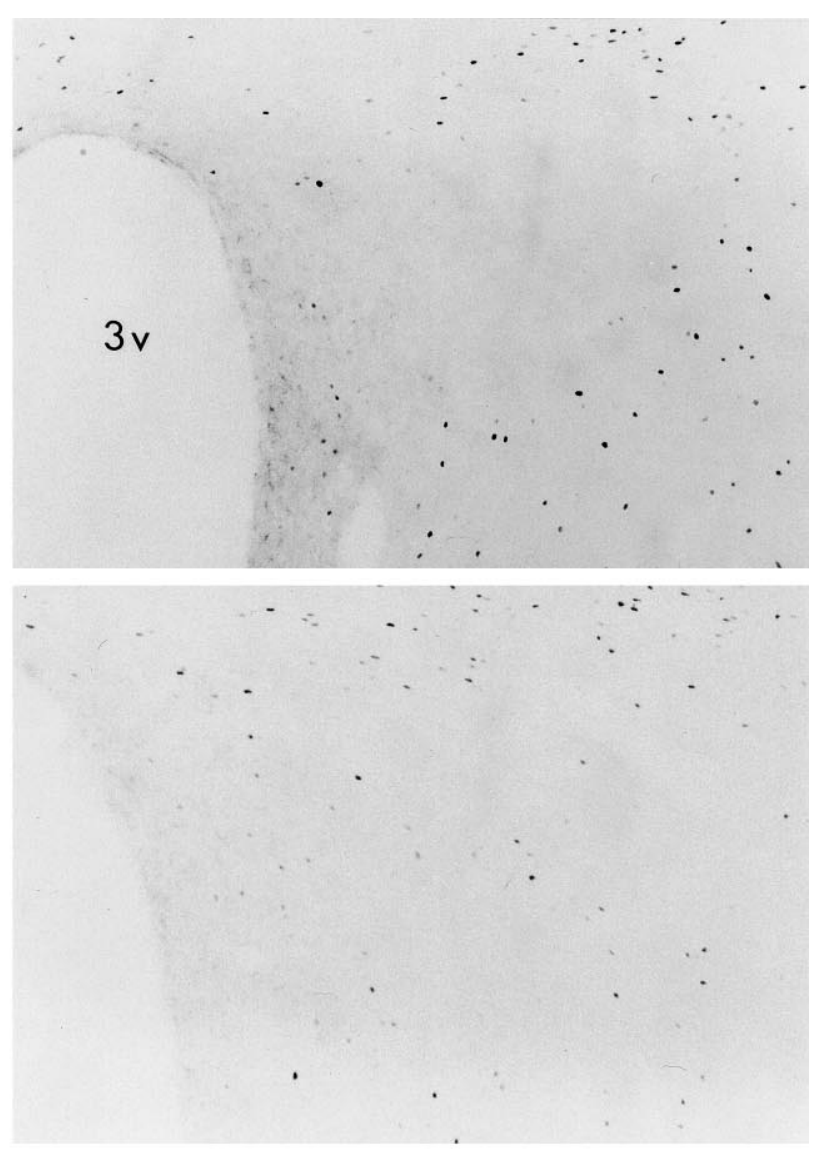

$\mathrm{EHOH}$

Figure 10. Effects of three consecutive daily intragastric injections of the vehicle or alcohol $(3.0 \mathrm{gm} / \mathrm{kg})$ on c-fos protein levels in the PVN of rats injected with alcohol $(3.0 \mathrm{gm} / \mathrm{kg}) 7 \mathrm{~d}$ later. Bright-field photomicrographs illustrating c-fos protein in the PVN of rats injected with alcohol 60 or $180 \mathrm{~min}$ earlier are shown. $3 v$, Third ventricle. Magnification, $340 \times$.

\section{Effects of preventing the ACTH and corticosterone response to the initial alcohol treatment on hormonal responses to the second alcohol challenge}

In this experiment, we investigated the contribution of increases in plasma ACTH and corticosterone release induced by the initial alcohol challenge on the subsequent blunting of the HPA axis of rats rechallenged with the drug. A first series of preliminary experiments was performed to determine whether the potent CRF antagonist astressin would be able to prevent the ACTH and corticosterone responses during the initial alcohol treatments. We found that the subcutaneous injection of astressin at 10 $\mathrm{mg} / \mathrm{kg} 60 \mathrm{~min}$ before alcohol injection achieved this aim and maintained plasma ACTH and corticosterone levels below 80 $\mathrm{pg} / \mathrm{ml}$ and $30 \mathrm{ng} / \mathrm{ml}$, respectively. This regimen was therefore used in the experiment illustrated in Figure 6, which compares the ACTH responses to an acute alcohol challenge $(3.0 \mathrm{gm} / \mathrm{kg})$ delivered $7 \mathrm{~d}$ after a series of three daily alcohol treatments $(3.0$ $\mathrm{gm} / \mathrm{kg}$, i.g.) in rats pretreated with the vehicle or astressin. Vehicle pretreatment, whether or not preceded by astressin, led to the expected rise in plasma ACTH levels when the animals were acutely challenged with alcohol $(3.0 \mathrm{gm} / \mathrm{kg}) 7 \mathrm{~d}$ later. Alcohol pretreatment induced the expected blunting of the ACTH response to a second drug challenge, an effect that was not significantly reversed or altered by astressin at the time of the initial alcohol injections. These results indicate that blunting the ACTH and corticosterone release during the initial alcohol challenge did not prevent the development of neuroendocrine tolerance that characterizes our model.

\section{Changes in the appearance of immediate early genes, taken as an index of neuronal activation, during the second alcohol challenge}

The protocol was similar to that used for Figures 1 and 2, and rats were pretreated with the vehicle or alcohol $(3.0 \mathrm{gm} / \mathrm{kg}) 7 \mathrm{~d}$ before a vehicle or alcohol rechallenge. The appearance of the immediate early genes c-fos and NGFI-B was taken as an index of hypothalamic neuronal activation in response to the second challenges. A 30, 60, 120, and 180 min time course was chosen because it allowed us to detect potential changes both in peak hypothalamic responses as well as in the pattern of these responses. NGFI-B mRNA signals were not detected in the PVN after vehicle injection (data not shown). On the other hand, a significant upregulation of NGFI-B transcripts was observed after alcohol treatment, but this response was markedly blunted in alcohol-pretreated rats (Figs. 7, 8). Similar results were obtained with c-fos mRNA levels in the PVN of the hypothalamus (Fig. 9). Because of the possibility that alcohol might differentially alter gene transcription and translation, in particular by influencing mRNA stability, we then decided to confirm results obtained by also measuring protein levels, an approach that for technical 
reasons was only possible for c-fos. We observed that although in vehicle-pretreated rats alcohol significantly increased levels of the c-fos protein measured 60 or 180 min later, this change was markedly blunted in animals pretreated with the drug (Fig. 10).

\section{DISCUSSION}

We show here that one daily intragastric injection of alcohol for $3 \mathrm{~d}$ produced a significant and long-lasting decrease in the ability of the HPA axis to respond to a second alcohol challenge. We further demonstrate that repeated treatment was necessary because rats injected with alcohol only once showed no change in their subsequent ACTH response. Finally, we found that this phenomenon of selective tolerance did not take place immediately, because ACTH release was undiminished on the third day of the three daily alcohol injections. This latter observation suggests that we are not dealing with a phenomenon of behavioral habituation similar to that described in rats repeatedly exposed to foot shocks or forced swimming (Kant et al., 1985).

The blunted ACTH and corticosterone release that we observed was unexpected in view of several findings showing that previous activation of the HPA axis usually results in increased responsiveness to subsequent challenges. For example, repeated exposure to a particular stressor tends to facilitate the ACTH and corticosterone response to a subsequent novel acute stressor (Hennessy, 1991; Marti et al., 1994), a phenomenon that has been attributed to increased CRF expression in the hypothalamus (Makino et al., 1995) and to changes in the sensitivity of the HPA axis to steroid feedback (Akana et al., 1992). Also, a single intraperitoneal injection of $\mathrm{IL}-1$ is reported to prolong the ACTH response to a second challenge, whether it is immune (IL-1 injection) or nonimmune (exposure to foot shocks) (Schmidt et al., 1995). In this model, increased median eminence levels of VP have been held responsible for the changes in HPA axis activity (Dijken et al., 1993). Finally, there is the well known example of the permanent increase in HPA axis function in rats exposed to maternal deprivation during neonatal development (Stanton et al., 1988; Rosenfeld et al., 1991; Suchecki et al., 1993; Viau et al., 1993), a response in part caused by an upregulation of CRF in nerve terminals (Ladd et al., 1996). It therefore seems that, in the present model, alcohol exerts an influence that is unique in its ability to dampen further responses of the HPA axis.

We had observed previously that rats exposed to various noxious stimuli on the last day of a 7 to $10 \mathrm{~d}$ alcohol diet released less ACTH and corticosterone than did control animals, but this phenomenon was not caused by decreased pituitary responsiveness to CRF (Lee and Rivier, 1995). The present finding that rats exposed previously to alcohol can adequately release ACTH when challenged with electroshocks several days later suggests that, in these animals also, CRF remained a potent secretagogue of ACTH release. On the other hand, although animals fed the alcohol diet responded to VP with significantly blunted ACTH secretion (Lee and Rivier, 1995), such was not the case in the paradigm discussed here. We therefore hypothesized that in the model of selective tolerance, an initial exposure to alcohol prevented hypothalamic neurons from responding to a second drug challenge. To investigate this possibility, we measured the appearance of the immediate early genes NGFI-B and c-fos in the PVN, which is the siege of CRF perikarya (Swanson et al., 1983). We show here that, indeed, a subsequent acute injection of alcohol resulted in the appearance of lower NGFI-B and c-fos mRNA levels in rats previously administered this drug, compared with animals administered the vehicle. Although additional studies are necessary to demonstrate unambiguously whether this change took place in CRF and/or VP cell bodies, the fact that these immediate early genes were primarily found in the pPVN suggests that it probably corresponded to a dampening in the activity of CRF perikarya. Our results therefore indicate that the neuroendocrine hyporesponsiveness we observed may arise from a relatively slow developing, although long-term, effect of the drug on afferent pathways to the PVN and/or on the ability of CRF neurons to mount an adequate response to the second alcohol challenge.

We also considered the potential influence of another mechanism, namely, the effect of increased hormone levels during the initial drug challenge. We show here that when we blocked the $\mathrm{ACTH}$ and corticosterone response to the three repeated intragastric alcohol injections with a potent CRF antagonist, we did not alter the ability of the initial course of alcohol treatments to induce a phenomenon of neuroendocrine tolerance to the drug. These results agree with the finding that foot shocks, which also elevate ACTH and corticosterone levels, were not able to duplicate the long-term inhibitory influence of alcohol. They also suggest that widely operative mechanisms controlling PVN responses to stressors, such as those responsible for the ability of the hippocampus to regulate the negative feedback of glucocorticoids (Jacobson and Sapolsky, 1991; Feldman and Weidenfeld, 1993), are probably not of primary importance. It must be noted that alcohol and shocks, although they both stimulate the pituitaryadrenal axis, also exert influences on the brain that are distinct from each other and that may account for their differential influence in our paradigm. One feature that distinguishes these two stresses is that even a short course of alcohol treatment can induce withdrawal (Buck and Harris, 1991), which results in a course of brain activation (Matsumoto et al., 1993) most probably not present in shocked rats. A detailed study of the response of the hypothalamus during and after exposure to alcohol or shocks will be necessary to probe this hypothesis. It is also possible that alcohol pretreatment decreases the brain levels of a neurotransmitter that participates in the ability of the drug, but not of shocks, to release ACTH. One such candidate is serotonin, a stimulator of CRF-dependent pathways (Gartside and Cowen, 1990; Fuller, 1992; Pan and Gilbert, 1992; Calogero et al., 1993), which is inhibited by repeated or prolonged drug treatment (Carmichael and Israel, 1975; Woods and Druse, 1996) but which does not seem to be involved in physicoemotional stresses (Harbuz et al., 1993).

To our knowledge, this is the first report that any stimulus, given for a relatively short time, causes a long-lasting selective tolerance with regard to neuroendocrine responses. Alcoholism is a disease that affects between 8 and $10 \%$ of the population. If we accept the concept that some of the individuals who abuse alcohol do so in part because of the changes the drug induces in their CNS, it seems reasonable to propose that if such changes cannot be achieved with a given dose of alcohol, these individuals may consume more of the drug in an attempt to regain the wanted changes. A drug exerts its reinforcing effects via a number of distinct actions, including the ability to stimulate brain circuitries involved in the reward system and to induce symptoms of withdrawal that can only be averted by resuming drug consumption (Nestler et al., 1993; Altman et al., 1996; Koob, 1996). We suggest that our studies may provide the basis for a testable, neuroendocrine-based hypothesis of vulnerability to alcohol abuse. 


\section{REFERENCES}

Akana SF, Dallman MF, Bradbury MJ, Scribner KA, Strack AM, Walker C-D (1992) Feedback and facilitation in the adrenocortical system unmasking facilitation by partial inhibition of the glucocorticoid response to prior stress. Endocrinology 131:57-68.

Altman J, Everitt BJ, Glautier S, Markou A, Nutt D, Oretti R, Phillips GD, Robbins TW (1996) The biological, social and clinical bases of drug addiction: commentary and debate. Psychopharmacology (Berl) $125: 285-345$

Antoni FA (1993) Vasopressinergic control of pituitary adrenocorticotropin secretion comes of age. Front Neuroendocrinol 14:76-122.

Brown M, Fisher L (1990) Regulation of the autonomic nervous system by corticotropin-releasing factor. In: Corticotropin-releasing factor: basic and clinical studies of a neuropeptide (deSouza E, Nemeroff CB, eds), pp 292-298. Boca Raton, FL: CRC.

Buck KJ, Harris RA (1991) Neuroadaptive responses to chronic ethanol. Alcohol Clin Exp Res 15:460-470.

Cador M, Cole BJ, Koob GF, Stinus L, LeMoal M (1992) Central administration of corticotropin releasing factor induces long-term sensitization to D-amphetamine. Brain Res 606:181-186.

Calogero AE, Bagdy G, Moncada ML, D'Agata R (1993) Effect of selective serotonin agonists on basal, corticotrophin-releasing hormone- and vasopressin-induced $\mathrm{ACTH}$ release in vitro from rat pituitary cells. J Endocrinol 136:381-387.

Carmichael F, Israel Y (1975) Effects of ethanol on neurotransmitter release by rat brain cortical slices. J Pharmacol Exp Ther 193:824-834

Dallman MF (1993) Stress update-adaptation of the hypothalamicpituitary-adrenal axis to chronic stress. Trends Endocrinol Metab 4:62-129.

Dallman MF, Strack AM, Akana SF, Bradbury MJ, Hanson ES, Scribner KA, Smith M (1993) Feast and famine: critical role of glucocorticoids with insulin in daily energy flow. Front Neuroendocrinol 14:303-347.

Deroche V, Piazza PV, Deminière J-M, Moal ML, Simon H (1993) Rats orally self-administer corticosterone. Brain Res 622:315-320.

Dijken HV, Groij DD, Sutanto W, Mos J, Kloet Ed (1993) Short inescapable stress produces long-lasting changes in the brain-pituitaryadrenal axis of adult male rats. Neuroendocrinology 3:119-121.

Fahlke C, Hard E, Eriksson CJP, Engel JA, Hansen S (1995) Consequence of long-term exposure to corticosterone or dexamethasone on ethanol consumption in the adrenalectomized rat, and the effect of type I and type II corticosteroid receptor antagonists. Psychopharmacology (Berl) 117:216-224.

Feldman S, Weidenfeld J (1993) The dorsal hippocampus modifies the negative effect of glucocorticoids on the adrenocortical and median eminence CRF-41 responses to photic stimulation. Brain Res 614:227-232.

Fuller RW (1992) The involvement of serotonin in regulation of pituitary-adrenocortical function. Front Neuroendocrinol 13:250-270.

Gartside SE, Cowen PJ (1990) Mediation of ACTH and prolactin responses to 5-HTP by 5-HT 2 receptors. Eur J Pharmacol 179:103-109.

Gulyas J, Rivier C, Perrin M, Koerber S, Sutton S, Corrigan A, Lahrichi S, Craig A, Vale W, Rivier J (1995) Potent, structurally constrained agonists and competitive antagonists of corticotropin-releasing factor (CRF). Proc Natl Acad Sci USA 92:10575-10579.

Harbuz M, Chalmers J, Souza LD, Lightman S (1993) Stress-induced activation of CRF and c-fos mRNAs in the paraventricular nucleus are not affected by serotonin depletion. Brain Res 609:167-173.

Hennessy M (1991) Sensitization of the plasma corticosterone response to novel environments. Physiol Behav 50:1175-1179.

Jacobson L, Sapolsky R (1991) The role of the hippocampus in feedback regulation of the hypothalamic-pituitary-adrenocortical axis. Endocr Rev 12:118-134.

Kant GJ, Eggleston T, Landman-Roberts L, Kenion CC, Driver GC, Meyerhoff JL (1985) Habituation to repeated stress is stressor specific. Pharmacol Biochem Behav 22:631-634.

Koob G (1996) Drug addiction: the yin and yang of hedonic homeostasis Neuron 16:893-896.

Koob GF (1990) Behavioral responses to stress-focus on corticotropin releasing factor. In: Stress: neurobiology and neuroendocrinology (Brown MR, Rivier C, Koob G, eds), pp 255-271. New York: Dekker

Ladd CO, Owens MJ, Nemeroff CB (1996) Persistent changes in corticotropin-releasing factor neuronal systems induced by maternal deprivation. Endocrinology 137:1212-1218.

Lamblin F, De Witte P (1996) Adrenalectomy prevents the development of alcohol preference in male rats. Alcohol 13:233-238.
Lee S, Rivier C (1993) Effect of exposure to an alcohol diet for ten days on the ability of interleukin- $1 \beta$ to release ACTH and corticosterone in the adult ovariectomized female rat. Alcohol Clin Exp Res 17:1009-1013

Lee S, Rivier C (1995) Altered ACTH and corticosterone responses to interleukin- $1 \beta$ in male rats exposed to an alcohol diet: possible role of vasopressin and testosterone. Alcohol Clin Exp Res 19:200-208.

Maier S, Strittmatter M, Chen W, West J (1995) Changes in blood alcohol levels as a function of alcohol concentration and repeated alcohol exposure in adult female rats: potential risk factors for alcoholinduced fetal brain injury. Alcohol Clin Exp Res 19:923-927.

Makino S, Smith MA, Gold PW (1995) Increased expression of corticotropin-releasing hormone and vasopressin messenger RNA (mRNA) in the hypothalamic paraventricular nucleus during repeated stress: association with reduction in glucocorticoid receptor mRNA levels. Endocrinology 136:3299-3309.

Marti O, Gavaldá A, Gómez F, Armario A (1994) Direct evidence for chronic stress-induced facilitation of the adrenocorticotropin response to a novel acute stressor. Neuroendocrinology 60:1-7.

Matsumoto I, Leah J, Shanley B, Wilce P (1993) Immediate early gene expression in the rat brain during ethanol withdrawal. Mol Cell Neurosci 4:485-491.

McEwen BS (1992) Stress and the brain: why is the adrenal cortex good for you? In: Stress and reproduction, Vol 86 (Sheppard KE, Boublik JH, Funder JW, eds), pp 31-38. New York: Raven.

Munck A, Guyre PM (1986) Glucocorticoid physiology, pharmacology and stress. Adv Exp Med Biol 196:81-96.

Munck A, Guyre PM, Holbrook NJ (1984) Physiological functions of glucocorticoids in stress and their relation to pharmacological actions. Endocr Rev 5:25-44.

Nestler EJ, Hope BT, Widnell KL (1993) Drug addiction: a model for the molecular basis of neural plasticity. Neuron 11:995-1006.

Ogilvie K, Lee S, Rivier C (1997a) Effect of three different modes of alcohol administration on the activity of the rat hypothalamic-pituitary-adrenal axis. Alcohol Clin Exp Res 21:467-476.

Ogilvie KM, Lee S, Rivier C (1997b) Role of arginine vasopressin and corticotropin-releasing factor in mediating alcohol-induced adrenocorticotropin and vasopressin secretion in male rats bearing lesions of the paraventricular nuclei. Brain Res 744:83-95.

Ottenweller JE, Servatius RJ, Tapp WN, Drastal SD, Bergen MT, Natelson BH (1992) A chronic stress state in rats: effects of repeated stress on basal corticosterone and behavior. Physiol Behav 51:689-698.

Pan L, Gilbert F (1992) Activation of 5-HT $\mathrm{HA}_{1 \mathrm{~A}}$ receptor subtype in the paraventricular nuclei of the hypothalamus induces $\mathrm{CRH}$ and $\mathrm{ACTH}$ release in the rat. Neuroendocrinology 56:797-802.

Piazza PV, Deroche V, Deminiere J-M, Maccari S, Le Moal M, Simon H (1993) Corticosterone in the range of stress-induced levels possesses reinforcing properties: implications for sensation-seeking behaviors. Proc Natl Acad Sci USA 90:11738-11742.

Rivest S, Rivier C (1995) The role of corticotropin-releasing factor and interleukin-1 in the regulation of neurons controlling reproductive functions. Endocr Rev 16:177-199.

Rivier C (1993) Acute interactions between cytokines and alcohol on ACTH and corticosterone secretion in the rat. Alcohol Clin Exp Res 17:946-950.

Rivier C (1996) Alcohol stimulates ACTH secretion in the rat: mechanisms of action and interactions with other stimuli. Alcohol Clin Exp Res 20:240-254.

Rivier C, Shen G (1994) In the rat, endogenous nitric oxide modulates the response of the hypothalamic-pituitary-adrenal axis to interleukin-1 $\beta$, vasopressin, and oxytocin. J Neurosci 14:1985-1993.

Rivier C, Vale W (1988) Interaction between ethanol and stress on ACTH and $\beta$-endorphin secretion. Alcohol Clin Exp Res 12:206-210.

Rivier C, Rivier J, Vale W (1982) Inhibition of adrenocorticotropic hormone secretion in the rat by immunoneutralization of corticotropinreleasing factor (CRF). Science 218:377-379.

Rivier C, Bruhn T, Vale W (1984) Effect of ethanol on the hypothalamic-pituitary-adrenal axis in the rat: role of corticotropin-releasing factor (CRF). J Pharmacol Exp Ther 229:127-131.

Rosenfeld P, Gutierrez YA, Martin AM, Mallett HA, Alleva E, Levine S (1991) Maternal regulation of the adrenocortical response in preweanling rats. Physiol Behav 50:661-671.

Schmidt ED, Janszen AWJW, Wouterlood FG, Tilders FJH (1995) Interleukin-1-induced long-lasting changes in hypothalamic corticotropin- 
releasing hormone (CRH)-neurons and hyperresponsiveness of the hypothalamus-pituitary-adrenal axis. J Neurosci 15:7417-7426.

Shaham Y, Rajabi H, Stewart J (1996) Relapse to heroin-seeking in rats under opioid maintenance: the effects of stress, heroin priming, and withdrawal. J Neurosci 16:1957-1963.

Simmons DM, Arriza JL, Swanson LW (1989) A complete protocol for in situ hybridization of messenger RNAs in brain and other tissues with radio-labeled single-stranded RNA probes. J Histotechnol 12:169-181.

Spencer RL, McEwen BS (1990) Adaptation of the hypothalamic-pituitary-adrenal axis to chronic ethanol stress. Neuroendocrinology 52:481-489.

Stanton M, Gutierrez Y, Levine S (1988) Maternal deprivation potentiates pituitary-adrenal stress response in infant rats. Behav Neurosci 102:692-700.

Suchecki D, Mozaffarian D, Gross G, Rosenfeld P, Levine S (1993) Effects of maternal deprivation on the ACTH stress response in the infant rat. Neuroendocrinology 57:204-212.

Swanson LW, Sawchenko PE, Rivier J, Vale WW (1983) Organization of ovine corticotropin releasing factor (CRF)-immunoreactive cells and fibers in the rat brain: an immunohistochemical study. Neuroendocrinology 36:165-186.
Taché Y, Mönnikes H, Bonaz B, Rivier J (1993) Role of CRF in stressrelated alterations of gastric and colonic motor function. In: Corticotropin-releasing factor and cytokines: role in the stress response (Taché Y, Rivier C, eds), pp 233-243. New York: New York Academy of Sciences.

Vale W, Spiess J, Rivier C, Rivier J (1981) Characterization of a 41 residue ovine hypothalamic peptide that stimulates the secretion of corticotropin and $\beta$-endorphin. Science 213:1394-1397.

vanRaaij MTM, Dobbe CJG, Elvers B, Timmerman A, Schenk E, Oortgiesen M, Wiegant VM (1997) Hormonal status and the neuroendocrine response to a novel heterotypic stressor involving subchronic noise exposure. Neuroendocrinology 65:200-209.

Viau V, Sharma S, Plotsky PM, Meaney MJ (1993) Increased plasma ACTH responses to stress in nonhandled compared with handled rats require basal levels of corticosterone and are associated with increased levels of ACTH secretagogues in the median eminence. J Neurosci 13:1097-1105.

Woods JM, Druse MJ (1996) Effects of chronic ethanol consumption and aging on dopamine, serotonin, and metabolites. J Neurochem 66:2168-2178. 